\title{
16 Evolving chemical, biological, radiological and nuclear (CBRN) terrorism
}

\author{
Intelligence community response \\ and ethical challenges
}

\author{
Patrick F. Walsh
}

\section{Introduction}

This chapter has three objectives. First it assesses briefly contemporary and emerging chemical, biological, radiological and nuclear (CBRN) threats from non-state actors. Secondly, it identifies capability challenges across "Five Eyes" intelligence communities (ICs) in managing CBRN non-state actor threats and how these can be addressed. Thirdly, noting the threat posed by CBRN terrorism and "Five Eyes" ICs capabilities to prevent, disrupt or mitigate them, the chapter outlines key ethical challenges for ICs in managing such threats. The chapter is divided into three sections: contemporary and emerging non-state actor CBRN threats, intelligence capability gaps and challenges, and ethical challenges.

\section{Contemporary and emerging non-state actor CBRN threats}

\section{Defining CBRN}

The term "CBRN" includes a range of threats from the weaponization of chemical, biological, radiological and nuclear agents by state and non-state actors. "CBRN" is a departure from the traditional nomenclature - "Weapons of Mass Destruction" (WMDs), "with all its Cold War connotations of massive effect and mutual deterrence" (Cornish 2007, 2). As discussed shortly, not all CBRN threats present an existential threat to humanity or even massive causalities of the kind depicted during the Cold War; where the former Soviet Union or the United States might have deployed tactical or strategic WMDs (particularly nuclear weapons).

A critical point of difference between "WMD" and "CBRN" weapons is the former's principal objective of significant and predictable devastation. In order to achieve this objective, WMD weapons have to be reliable, safely deployable and able to result in major destruction of localities and in the deaths of hundreds of thousands in order to deter an adversary. Throughout the Cold War to the present, only a few threat actors have developed large-scale WMD programmes that could result in significant and reliable widespread destruction of an enemy.

DOI: $10.4324 / 9781003164197-23$ 
In contrast, while some non-state actors have demonstrated an interest and even an intent to use WMD-related technologies, up to this point none has demonstrated the capability to weaponize chemical, biological, radiological or nuclear agents akin to a truly devastating military standard that state actors have achieved with their WMD programs. Additionally, non-state actors such as terrorists, who show an interest in WMD technologies, are likely to use a different strategic calculus for their deployment than military grade state actor programmes. For terrorists, widespread destruction and accurate delivery may be less important than reaping a propaganda dividend from damage of property or causing the deaths of several hundred (rather than thousands) of deaths. A rudimentary CBRN agent therefore offers another suite of weapons that some non-state actors may choose to use. Their deployment may not kill thousands of victims, but nonetheless could conceivably result in a large number of casualties as well as having profound psychological, social and economic effect on the target countries. In short, terminology (WMD vs. CBRN) matters to how ICs understand threats and plan capability responses against them.

\section{Non-state actor CBRN threat assessment}

\section{Chemical weapons and terrorism}

While the 1997 Chemical Weapons Convention (CWC) has provided normative constraint on most state signatories in abandoning their use, production and storage of military grade CWs, it has been less helpful in containing terrorist's use of such weapons. The CWC was not crafted with counter-terrorism in mind. ${ }^{1}$ It has focused on the large-scale military production of chemical agents - not smaller amounts that terrorist groups would likely use. Within the current CWC verification regime it is also impossible to guarantee whether a few kilograms of toxic chemicals would be detected before they were used by a terrorist group. Additionally, a failure by all CWC signatory states to implement strictly all of its articles means it is easier potentially for terrorists to acquire a chemical weapon capability.

While the design and manufacture of advanced CWs will likely remain a technological challenge to many non-state actors, the intent by some to use them remains. Reliable data remains sketchy, though the Monterey WMD terrorism database reports for the period 1988-2004, 207 of the 316 CBRN incidents recorded involved CW (Ivanova and Sandler 2006, 423-48). These incidents, however, mostly involved the use of conventional explosives mixed with openly available chemicals to make them more deadly - or are failed attempts to weaponize chemical agents (Ivanova and Sandler 2006, 423-48).

It's clear that Al-Qaeda and its franchises have shown interest in the deployment of CWs and other WMDs. In 1998, bin Laden said that to acquire and use WMDs was his Islamic duty (Mowatt-Larssen 2010). Abu Musab al Zarqawi, the leader of Al-Qaeda in Iraq, planned to utilize his network to carry out multiple ricin and cyanide attacks in the London Underground from 2002 to 2003, though they were thwarted by the Metropolitan Police Service (Rathore 2016, 5). 
Additionally, other Al-Qaeda franchises in Iraq (e.g. Ansar al-Islam) had begun to experiment with chemical and toxic weapons and declare their intent to obtain CW (Ackerman and Jacome 2018, 29; Pita 2007, 480-511).

The only attack, however, that involved a standard CW agent - the Tokyo Sarin gas attacks by Aum Shrinikyo in 1995 - showed how difficult it is to mount an effective CW attack - even for an organization with high levels of expertise and sufficient funding (Danzig et al. 2012; Kaplan and Marshall 1996; Cornish 2007; Tucker, Miller, and Lynn-Jones 2000). Shinrikyo's attempts to synthesize Sarin cost as much as $\$ 30$ million, involved 80 scientists and took a year or more to achieve (Cornish 2007, 6).

While there remain technical barriers for most terrorist groups in building a conventional military grade $\mathrm{CW}$, access to ready-made weapons could occur through theft or via state sponsorship. Likely sources are stockpiles in fragile and unstable states such as Syria, Iraq, Libya and North Korea. International retributions, however, including threats of regime change or economic sanctions may discourage states providing CWs to terrorists. Nonetheless, the instability of such regimes, including corrupt officials who have access to weapons, may facilitate access within these states. For example, recent reports from Iraqi officials (citing intelligence reports) suggested that the Islamic State (IS) during 2014 gained access to weapons stockpiles of the Syrian and former Iraqi regimes (Berger 2015, 423-48).

What of Islamic State (IS) use of CW? As IS grew in power (2014 to July 2017) the terrorist group reportedly used chlorine and sulphur mustard gas in Iraq and Syria several times. The number of actual attacks is still debateable, but researchers put them in the range of 37 to 76 times (Binder, Quigley, and Tinsley 2018, 27; Rathore 2016, 7; Strack 2017, 19-24). In 2014, IS was able to seize, purchase or craft military hardware that could be used in a chemical weapon programme in parts of Syria and Iraq. During the Caliphate's physical expansion in Syria, IS forces deployed chlorine, sulphur mustard, phosphine and other toxic industrial chemicals such as vinyl-trichlorosilane, for tactical purposes - the first chemical warfare agents introduced onto the battlefield since the Iran-Iraq War. However, the mode of delivery of IS CW attacks seems to have been not in the same vein as classical WMD weaponry, instead involving the insertion of chemical substances into shells and firing them rather than the deployment of any sophisticated weaponry system (Elvey 2015).

With the final destruction of the Caliphate in 2019, the threat from IS including its capability to deploy CWs or other "WMD like weapons" has declined. Nonetheless, IS recruiters and sympathizers continue to message an interest in developing a CBRN capability. Given IS did occupy areas of Iraq where CWs were stored and actually deployed (however crudely) one cannot discount fully a scenario where an IS lone actor could smuggle some $\mathrm{CW}$ material into the West and/or launch a rudimentary attack by accessing one or more poorly secured precursor chemicals or facilities where agents are stored (Ackerman and Jacome 2018, 30).

Recent developments in dual-use chemistry and related technology mentioned earlier (e.g. the production of toxic industrial chemicals and advanced chemical 
weapons) might also be attractive to some terrorist groups to weaponize in the future. The relatively weak international regulation and safety mechanisms around their manufacture, storage and transport in some nations remain a vulnerability.

\section{Biological weapons and terrorism}

In recent years, the debate around biological weapons (BWs) and non-proliferation has increasingly focused on non-state actors and terrorist groups in particular. CBRN researcher Seth Carus assessed that there were "at least 25 'distinct subnational actors' who were known to have 'shown concerted interest' in acquiring BW, with at least eight of them known to have been successful" (Carus cited in NDU 2003, 5). The experiments of Aum Shrinikyo with Anthrax and Ebola, the religious cult the Rajneeshees that poisoned salad bars with Salmonella typhimurium in 1984, as well as the 2001 Anthrax attacks allegedly by United States Army Medical Research Institute of Infectious Diseases (USAMRIID) microbiologist Bruce Ivins are well documented examples (Carus 2000, 115-37; Rosenau 2001; Walsh 2018). ${ }^{2}$

After 9/11, Al-Qaeda had demonstrated an interest in developing BW agents. Following the 2001 coalition forces' invasion of Afghanistan, US soldiers found technical documents and equipment in a biological weapons laboratory under construction near Kandahar (Walsh 2018, 29-31; Tenet 2007, 278-9). The capture, interrogation or death of most key Al-Qaeda operatives associated with its fledgling bio-weapons programme constrained further efforts by the group to continue down this pathway.

Since the ouster of Al-Qaeda from Afghanistan the evidence has remained mixed on whether other Al-Qaeda affiliated groups have developed technical expertise in BWs - though the interest to do so seems to be clearer (Walsh 2018, 30; Koblentz 2009, 223-4). More recently there is also some evidence that IS has had ambitions to develop BWs when a laptop was seized in 2014 from one of the group's hideouts in Syria. The laptop, owned by a Tunisian, who had studied chemistry and physics at universities in Tunisia, revealed thousands of files pertaining to producing biological weaponry (Doornbos and Moussa 2014). Other reporting, though of questionable credibility, suggests IS had plans to recruit scientists in Iraq and the West to develop BWs (Elvey 2015; Doornbos and Moussa 2014).

The "Five Eyes" countries' understanding of state and non-state actor BW proliferation has not been robust over the last 50 year period (SSCI 2004; Flood 2004; Butler 2004). The reasons why assessment of bio-threats and risks was not optimal relates to a number of complex capability issues. Some of these issues are discussed in the following section, but space is limited and the reader seeking detailed understanding of capability issues can go to Walsh (2018). Suffice it to say, a lack of understanding by "Five Eyes" ICs has had real policy implications since 9/11 about scoping bio-threats and risks and how to manage them. The faulty intelligence assessment on WMD provided prior to US-led coalition invasion of Iraq in 2003 is the most well-known example. While debates continue within IC and policy circles on what factors might drive contemporary and 
emerging bio-threats and risks - they have coalesced around two broad threat/risk typologies: stolen biological agents and dual use research and synthetic biology. I will focus on the latter as this area is currently of greatest concern by ICs and the scientific community. ${ }^{3}$

\section{Dual use research and synthetic biology}

Dual use research relates to research of dangerous biological agents that might be weaponized, and the publication of same, which potentially could be disseminated to threat actors for use (Walsh 2018, 41). It remains an open debate on whether criminals and terrorists will exploit biotechnology and synthetic biology research developed for legitimate purposes (e.g. health care, energy and food supply) for harm or profit. Assessments of threat and risk diverge mainly around two analytical frameworks: technological (determinism) and socio-technological. The technological determinists argue that the upsurge in biotechnological advancements will make the access, use and exploitation of relevant knowledge and skills easier and cheaper for those with malevolent intentions (Chyba 2006; Carlson 2003; Petro and Carus 2005). Some of the consequences of the industrialization of biology add weight to their arguments about easier access and use of biotechnology. For example, the entire human genome sequenced by 2013 took a team of scientists 13 years and $\$ 500$ million to identify 20,500 genes. Today, the human genome can be sequenced in a day using bench top equipment costing around $\$ 1000$ (Walsh 2018, 44).

In contrast, the socio-technologists do not discount that criminals, and terrorists may exploit advances in synthetic biology and technology - yet argue access to knowledge and skills do not necessarily translate into threat actors adeptly exploiting these in order to produce a bio-weapon. They argue that other sociotechnical variables will impact on choices made to exploit and weaponize biology (Vogel 2008; 2013). Both intellectual perspectives have something to offer "Five Eyes" ICs in improving their assessments of emerging bio-threats and risks.

What types of specific bio-threats are evolving? Assessing intention and capability to misuse dual use biological research remains difficult because the science is moving rapidly - making it difficult to get a "fix" on where vulnerabilities for malevolent exploitation are located. Such difficulties are amplified given the challenges all ICs confront when adapting to technologically enabled threats more broadly (e.g. cyber).

Leaving aside the assessment difficulties, I have argued elsewhere that there are at least three areas where "Five Eyes" countries can start developing better knowledge of bio-threats and risks. These are: bio-unabombers, identity theft and biopiracy. In regard to bio-unabombers, biotechnology is big business particularly in the United States (Walsh 2016, 341-67; 2018, 41-51). ${ }^{4}$ Given the acceleration in biotechnology and synthetic biological sciences - probability alone suggests that there will be more individuals (some mentally unstable) with a range of grievances (e.g. personal, psychological, political and religious) working in the biological sciences and some may escalate these to acts of violence. Disgruntled 
insiders (scientists), who can make a synthetic organism and obtain natural organisms under lock and key in highly regulated high containment labs, are uniquely placed under the disguise of a bigger legitimate scientific project to become bio-unabombers (Walsh 2018, 41-51).

Secondly, "identity" - long a facilitator of crime and terrorism in other contexts - is also likely to be a developing concern. The increase in DNA holdings in various government departments and the private sector provide greater opportunities to steal or manipulate DNA (Walsh 2018, 41-51). Thirdly, bio-piracy could become a greater bio-threat and risk in "Five Eyes" countries. Recent developments in drugs, vaccines and medicines can be manipulated via newer gene editing techniques like CRISPR, Finger Nuclease and Talen (see in the following).

\section{Radiological weapons and terrorism}

In contrast to BWs, where terrorist's production of them could be constrained by insufficient skills and knowledge, the wider global availability of radioactive material has long formed the basis for arguments that such groups would more likely weaponize them instead. Different isotopes are used in large quantities in various civilian applications (e.g. radium or caesium isotopes used in cancer treatments). The dual use nature, common use globally, and in some locations insufficient security and monitoring arrangements related to storage, provide terrorist groups with easy access to dangerous radioactive substances that can be weaponized with little technical expertise or value added from them prior to use. Radioactive material may also be obtained from the civilian nuclear fuel cycle, for example by harvesting it from widely used mixed oxide fuel (MOX), which is a relatively simple technical procedure (Balatsky and Severe 2019, 357-87). While detection of radiation is not uncommon in ports, it is likely that terrorist groups would procure the material locally from sources mentioned earlier. Accessing radioactive materials could be easier than developing $\mathrm{CWs}$ or BWs - but they are nonetheless hazardous to handle and transport.

Assessments diverge on the lethality and damage caused by a radiological attack. The impact would depend on a number of variables, including the force of the explosion, the type of radioactive material used, the particle size of the dispersed material, weather conditions and countermeasures (Rosoff and Winterfeldt 2007; Cirincione and Wilson 2015). However, many analysts assess that the number of casualties would be relatively low and probably not reach three figures (Rosoff and Winterfeldt 2007; Cirincione and Wilson 2015). Nonetheless, damage to property and the disruption of people's lives and economic activity could be significant if the bomb was released in a crowded downtown financial area or a critical infrastructure zone such as a port.

While it isn't trivial to produce a dirty bomb with optimal particle size and dispersion pattern to maximize casualties, it is considerably simpler than constructing a nuclear device, as no fission or fusion reactions have to be triggered. ${ }^{5}$ Nonetheless, terrorist groups would still need to have some knowledge about the physical form of the radiation source and what the optimal amount and types of 
explosives would be required to ensure a wide dispersal of radiation (Ackerman and Jacome 2018, 26).

In spite of the potential viability of attack scenarios just mentioned, radiological attacks are not common. This might be because they don't have the same kind of immediate kinetic lethality caused by simpler conventional explosives. Similarly, like other CBRN tactics they also carry significant operational risks of substantial retaliation by the country that falls victim to such an attack.

In 2015, media reporting by the Associated Press suggested that IS was interested in using a dirty bomb and may have tried to acquire radiological material from gangs with Russian connections (Butler 2015). It is unclear however, if IS successfully purchased it or if it was weaponized or used in any attacks.

\section{Nuclear weapons and terrorism}

Reports vary on whether non-state actors have either attempted or intend to acquire nuclear weapons (Mueller 2019, 5; McIntosh and Storey 2018, 289-300; Allison 2018). Further assessment of the validity of terrorist's intent and capability to develop nuclear weapons is therefore critical. From the intent perspective, Al-Qaeda leadership showed interest in developing nuclear capability - with Bin Laden quoted in an interview that the acquisition of a nuclear weapon (and other WMDs) is a "religious duty" of Muslims (van de Velde 2010, 682-99). However, despite Al-Qaeda's desire to use CBRN against enemies, the threat never materialized (Rathore 2016, 5), particularly after sustained counter-terrorism action either destroyed or degraded its bases in Afghanistan after 2001. According to experts at NATO's WMD Non-Proliferation Centre, IS has already acquired the knowledge and in some cases human expertise to use CBRN material (Boyle 2015). But it's unclear the extent to which any IS members developed a viable nuclear bomb during or after the Caliphate years.

Several terrorist groups have "metastasized" from Al-Qaeda and IS, and the pressing question is what intent and capability will even more radicalized and potentially catastrophic terrorists have to develop nuclear weapons? Such groups may calculate that acquiring and using them is worth the effort. Unlike the development or acquisition of chemical, biological and even radiological weapons, building a nuclear bomb remains extremely difficult for non-state actors. Producing fissile material from raw products would require a focused and extended process in either the enrichment of uranium or the chemical separation of plutonium - that will likely be too complex, costly and detectable for most currently known terrorist organizations to realistically undertake. Instead of conventional nuclear weapons, it is possible that some terrorist groups could build an improvised nuclear device, if they were able to obtain enough weapons-grade uranium or plutonium (Cornish 2007, vii).

Another commonly cited scenario is terrorist groups could either steal or be given nuclear weapons by vulnerable state actors such as Pakistan or countries of the former Soviet Union. The theft of nuclear weapons is feasible from countries where political and security risks reduce confidence in the safe storage of these 
weapons by their governments. But it is a risky gamble for these states and their officials as it would invite instant retaliation from "Five Eyes" states (Weiss 2015, 75-87; Clarke 2013, 98-114).

In terms of emerging threat trajectories, as discussed shortly, there are other security concerns around the emergence of an "internet of nuclear things" and the digital nature of additive manufacturing, which might provide some non-state actors with new means to subvert nodes in nuclear supply chains at which proliferation activities have traditionally been detected (Hoffman and Volpe 2018, 102-13; Kroenig and Volpe 2015; Fey 2017; Bajema and DiEuliis 2017; Shaw 2017; Hvistendahl 2016; Kelly 2017).

\section{Intelligence capability gaps and challenges}

\section{Detection of emerging threats}

The IC's ability to assess emerging CBRN state-based threats can be difficult enough given states can engage in well-organized deceptive strategies and claim suspicious activities are part of legitimate research, development and commercial activity. It is even more difficult for ICs to assess the emerging CBRN threat posed by terrorists. Terrorist "CBRN programmes" are not scaled up like their statebased counterparts. They typically do not consist of large research and industrial enterprises nor involve many people or the regular movement of CBRN-related goods and services. Being in most cases the opposite of state-based CBRN programmes reduces even further the likelihood of detection and disruption. Compounding the detection challenge of non-state actor CBRN threats is that analysis of them has often relied on sub-optimal empirical theorizing. Analytical extrapolations have tended to rely only on a handful of prominent cases to understand how threats will evolve (Binder and Ackerman 2019, 1).

Several authors have discussed how to improve CBRN terror threat detection (Tucker, Miller, and Lynn-Jones 2000; Caves and Carus 2014; Maurer 2009; Koblentz 2009), but such efforts remain difficult due to very few CBRN attacks by terrorists. A key barrier to better threat detection has also been the different classifiers scholars have used to record CBRN terrorism. In recent years, the University of Maryland's Profiles of Incidents Involving CBRN and Non-state Actors (POICN) Database has recorded more than 517 CBRN terrorism-related events from 1990 to the present and offer potentially a more accurate way to classify such attacks (Binder and Ackerman 2019, 1).

In addition to classification issues, there remains a lack of certainty and consensus from within ICs and scholars about future CBRN attack vectors. As noted earlier, with the collapse of the Caliphate in March 2019, for example, it is even less clear what number of IS and affiliated groups have retained/acquired skills/ knowledge convertible to potential CBRN attacks in the Middle East or by foreign fighters returning to home countries.

Improving threat detection on the intent, skills and knowledge of CBRN by lone actors/groups also includes greater collection effort against individuals 
who provide financial and logistical support to terrorist groups for such attacks. Such individuals/groups are points of vulnerabilities for any planned attack that ICs may be able to detect and disrupt early; though increasingly encrypted communications and the use of dark web sites by terrorists can make tracking their finances and logistics difficult. More focused collection efforts, including those of vulnerabilities in dual use technologies - will hopefully result in the accumulation of empirical evidence useful to informing better CBRN terrorist threat and risk assessment models used by ICs (Ackerman and Jacome 2018, 16; Zhang and Gronvall 2020; Walsh 2018, 79-83, 121-43; Habegger 2010, 49-58; Gentry and Gordon 2019, 215-34).

It is likely also that a deeper understanding of psychological factors to acquire, produce and use CBRN weapons through earlier psychological profiles of individuals and group members would be useful. In particular, ICs need to understand the behaviour of "insiders" working in economic sectors that produce CBRNrelated material vulnerable to their exploitation (Bunn and Sagan 2016). Threat actors could also be "outsiders" who can access material from insiders by purchasing it or by using blackmail or other threatening forceful behaviour.

Another dimension to improving threat detection relates to organizational and governance issues in "Five Eyes" ICs. These issues concern how ICs are structured, coordinated and led to manage the evolving non-state actor CBRN threat environment. Are organizational and internal leadership fit for purpose in managing CBRN terrorist threats into the future? And what agencies across "Five Eyes" countries are best suited to own the CBRN threat problem into the future? In the United States with a total of 17 intelligence agencies, there is an ongoing need for IC leaders, particularly the DNI, to review IC wide counter CBRN arrangement to ensure de-conflicted intelligence collection and analysis (Mauroni 2019, 2). The key governance issue for ICs in the foreseeable future will be how to fuse increasing volumes of CBRN-related information to develop better situational awareness. Another enduring governance dimension is how the IC leadership can more effectively bring in external technical expertise as well as ensuring that the analytical workforce also sustains an optimal level of expertise in CRBN issues. ICs also need to develop greater outreach to relevant dual use CBRN-related industries (Walsh 2021).

\section{Threat detection and technology}

Across the entire CBRN spectrum there is an increasing suite of dual-use technology available - making it easier and more affordable for terrorist groups to access and potentially weaponize. As noted earlier, assessing the significance of technology to future CBRN uptake by terrorists is fraught with inaccuracies. Care is warranted in avoiding overly technologically deterministic assessments given most terrorists are not operating at the cutting edge of science. Nonetheless, ICs need to investigate how quickly such technology can morph into commercialoff-the-shelf applications that could boost terrorist capabilities (Ackerman and Jacome 2018, 32). As new technologies become available for sale online, they 
can be purchased and quickly delivered around the globe - effectively resulting in what Ackerman and Jacome refer to as "the 'democratization' of the means of mass destruction" (Ackerman and Jacome 2018, 32). Additionally, any assessments of technological developments need to consider that the rate of change and length of time between major breakthroughs is continually decreasing (Ackerman and Jacome 2018, 32).

Space does not allow an exhaustive assessment of all CBRN related dual use technology. Instead in the next section I briefly list three dual use technology areas: $3 D$ printing/additive manufacturing, CRISPR and drones, which may be exploited by terrorist groups.

\section{D printing/additive manufacturing}

The rapid growth in 3D printing/additive manufacturing for legitimate science and technology sectors (e.g. medicine) also opens up opportunities for their illicit use by terrorists for CBRN weapons. The ability of a terrorist network to procure for example 3D printed nuclear components or their files is one example. Additive manufacturing provides avenues for cheaper, faster and stealthier methods for acquiring dual use sensitive information and technology where deception is more difficult to detect by ICs (Rid 2011; Anderson 2016; Albright, Brannan, and Stricker 2010).

There are a number of potential scenarios where terrorist groups could exploit current difficulties in the detection and movement of additive manufactured products and files. For example, 3D printing files of nuclear equipment could be shared with a terrorist group via a third party - thereby avoiding any export control detection (Fey 2017, 1-44).

\section{CRISPR}

Gene editing tools like CRISPR, which allow accurate genetic modifications achieved by the use of small strands of RNA to guide proteins (e.g. CAS protein) to a specific site in an organism's DNA, holds much promise for a range of medical treatments and other legitimate uses in bio-sciences. As noted earlier, the US IC has already expressed concerns that this technology could be weaponized by terrorists (Clapper 2016). But further work is required by ICs on what ways terrorist groups could exploit CRISPR.

\section{Drone swarms}

Conventional drones are already being exploited by some terrorist groups (Gibbons-Neff 2017; Warrick 2017; Sims 2018). Rapid development of smaller drone swarms, however, could also be used in a coordinated delivery of CBRN attacks in the battlespace or a metropolitan environment (Kallenborn and Bleek 2018). Again, further collection and analysis is required on how this technology can be exploited by threat actors. 


\section{Threat disruption}

Despite the potential for some terrorist groups to exploit CBRN-related dual use technology for attacks, ICs are progressing their understanding of technology, knowledge and skills, which can enhance their capabilities for CBRN detection and disruption. For example, developments in two multi-disciplinary fields (cyber and forensics) will likely continue to play an important role in CBRN terrorism threat disruption. We have seen how, for example, in the 2010 stuxnet attack on an Iranian uranium enrichment plant and other facilities, which introduced IC malware, can disrupt progression of CBRN terrorist capabilities (Mugavero et al. 2018, 52). In addition to investment by "Five Eyes" partners in offensive cyber intelligence capabilities (Vavra 2019), developments in forensic science are also useful in detecting and disrupting CBRN attacks. Limited space does not allow an exploration of the various forensic applications currently being developed. Some are sceptical of the role of forensics thus far in, for example, the unreliable detection rates of bio-agents in programmes such as the US Biowatch program (Walsh 2018, 182). But research efforts suggest that forensics will remain critical in the development of early sensor systems for countering CBRN terrorism (Zöller and Genzel 2018; Shea and Lister 2003; Walsh 2018; Kouzes et al. 2008, 383-400).

\section{Ethical challenges}

The key ethical challenge arising from CBRN terrorism relates to the moral duty "Five Eye" ICs have to protect both the lives of citizens and non-citizens from attacks. The ICs bear only some of the moral and institutional responsibility to protect society. Other state instruments (military, health, foreign ministries and dual use industries) also have a collective moral responsibility to protect society from CBRN terrorism (Miller 2006, 176-93). But in this chapter, the focus is on the IC's role.

In this last section, I outline how IC collection against potential CBRN terror attacks presents additional hitherto not well-understood ethical and policy dilemmas that require further assessment. Fulfilling a moral duty by the state to preserve life is contingent on ICs having situational awareness about the intent and capability of terrorists to launch CBRN attacks. This in turn, as noted earlier, relies on "Five Eyes" ICs improving the accuracy of CBRN threat detection capabilities that can more reliably direct where intelligence collection, analytic and operational resources are best allocated to prevent and disrupt attacks. Improving threat and risk assessment capabilities will require as noted earlier continued institutional improvements across ICs. In particular, improvements are required in governance arrangements within ICs and a greater focus on analytical expertise and performance. Additionally and perhaps even more importantly, ICs need to develop strategies for sustained and systematic engagement with experts outside the community, who will be better placed to advise how various CBRN technologies could be exploited by terrorists. ICs are engaging more with outside experts on CBRN technology issues, but they will also need to develop their own 
knowledge and skills about CBRN terrorist threat actors' intentions and capabilities through covert collection and rigorous analysis.

Given the grave psychological and physical consequences of even a small CBRN-enabled terrorist attack in Sydney, Washington DC or London, ICs need to conceptualize and operationalize a more expanded pro-active intelligence collection approach to this threat type. We have already witnessed in the period after 9/11 the growth in counter-terrorism policy and legislative powers that have lowered the threshold and expanded the kinds of collection that ICs are able to do on those suspected of being involved in terrorism offences (Cogan 2004; Walsh 2016, 51-74; Walsh and Miller 2016). For all ICs, these creeping powers while undoubtedly in many cases helping in the earlier identification of a group/ individual planning conventional terrorist attacks - have also sharpened debates in liberal democracies about the impact of collection on individuals' privacy and broader human rights. This includes the liberty for individuals, who might in some circumstances be subjected to preventative detention or control orders if suspected but not yet charged of being involved in terrorism as seen in the Australian context. While collection against known terrorists should align with principles of necessity, proportionality and discrimination, many of the enhanced proactive collection powers ICs now have at their disposal may be targeted (accidentally or by intent) at innocent citizens and thus potentially result in a violation of privacy and other human rights. Determining the extent of surveillance required in a counter-terrorism case will be decided by a range of contextual factors that will be different depending on the individuals involved (e.g. citizens, non-citizens, reasonable suspicion, foreign vs. domestic actors and immediacy of threat).

The ongoing debates about the impact of growing aggressive and permissive approaches to intelligence collection are also relevant to collection efforts against CBRN terrorism. However, given the discussion earlier of terrorists' potential exploitation of dual use technology, it is possible that ethical dilemmas posed by collecting against CBRN terrorism may grow beyond those seen in conventional terrorism. As noted earlier, a growing suite of knowledge, skills and technologies in the chemistry, biology, radiology and nuclear fields is providing significant advancements to fulfil legitimate human needs such as medicine and energy.

However, as seen acutely in the biological sciences and biotechnology sector, dual use technology can be exploited by bad actors for malevolent ends. The ability by ICs to gain more accurate evidence-based threat assessments is therefore dependent on collecting a great deal more information about the skills and knowledge of people working in a range of public and private organizations across the diverse chemical, biological, radiological and nuclear sectors. Space limitations do not allow a comprehensive analysis of all the ethical dilemmas arising from an expanded collection across all CBRN-related industries. But considering briefly the biological and biotechnology sector, it's clear that ICs would potentially be interested in information from a range of different experts working across a diverse number of contexts such as private biotech companies, universities, public research institutes, hospitals, graduate students, military personnel, lab biosafety officials, biology suppliers, forensic scientists and scientific publishers. Detection 
of $\mathrm{CBRN}$-enabled terrorist threats will remain difficult for all the reasons discussed earlier, particularly if plans and activities are hidden in legitimate dual use research. Hence the prevention and disruption of such threats will likely rely on more invasive collection from the experts and contexts just mentioned - at least for the case of biologically enabled attacks. What could more invasive collection in the biological sciences environment mean?

Firstly, it would go beyond the standard security clearance testing that all scientists must undergo if they wish to work with biological select agents. These are mandated legislatively, and people working with dangerous pathogens accept these checks as a condition of employment despite them being intrusive. Nonetheless, other more invasive collection strategies could be targeted against either suspects personally; the environment where they work; or a setting in which there may be some security concerns. Invasive collection might include enhanced CCTV surveillance in a facility under investigation, IC or police questioning of persons and other co-workers, more regular security checks, examination of hard copy and digital files and equipment, security vetting of research results and publications and accessing medical/mental health records.

While some IC agencies across "the Five Eyes" have developed trusting and productive relationships with important stakeholders in the biology and biotechnology sector such as the FBI's research community outreach initiatives, these efforts are by no means uniform across either the US IC or other "Five Eyes" countries. Therefore, in addition to developing better collection and analytical capabilities to assess and disrupt CBRN terrorist threats, ICs need to consider the ethical consequences that may arise from additional invasive intelligence collection in dual use technology and research contexts. The actual ethical risks arising from collection across CBRN dual use research and technology sectors cannot be generalized and will rely on a range of variables including but not limited to collection methods (e.g. meta data, social media, mental health history records), threat evolution (reports of "suspicious activity" vs. direct evidence of conspiracy to commit terrorism), contexts (e.g. military, espionage, criminal, terrorism) and the nature of the target (physical location, history and provenance of all relevant information).

While more work is now being done to examine the ethical dimensions of dual use research and technology in the broader sense, particularly in synthetic biology (National Academies of Sciences, Engineering, and Medicine et al. 2017; Miller and Selgelid 2007; Miller 2018), it's clear that an important next step must be a deeper ethical and policy analysis of how intelligence collection across the CBRN dual use spectrum impacts on the privacy and human rights of those working in these sectors. Such an endeavour would not only help to address the public's concerns over the powers and legitimacy of ICs, but also help to improve the efficacy of actual collection approaches under taken.

\section{Conclusion}

This chapter has surveyed the emerging CBRN terrorist threat space. There are a number of assessment uncertainties for ICs, but it is likely given resource 
constraints that any CBRN programmes will be smaller scale than conventional state-based WMD programmes. Likewise the impact of such attacks, though disruptive and psychologically profound, will not result in mass casualty levels associated with WMD programmes.

"Five Eyes" ICs are nonetheless gaining a greater understanding of threat and risk trajectories for CBRN terrorism. However, ICs need to develop sustained collection and analysis against potential attack vectors and more nuanced understanding of the psychological, social and technical drivers influencing terrorist's interest and capability in CBRN dual use technologies. The IC's ability to assess threat, risk and then prevent/disrupt CBRN terrorist attacks will increasingly rely on effective external and internal governance that can better integrate relevant and limited collection and analytical assets. Finally, given the diversity of the dual use technology and research sector, and in order to more effectively prevent and disrupt CBRN terrorism, it is likely that IC surveillance will need to expand further into these sectors. This will raise additional policy and ethical dilemmas for ICs and citizens of liberal democratic states which at this point are not well understood.

\section{Notes}

1 Though now the Organisation for the Prevention of Chemical Weapons (OPCW) has recently developed additional security and legal support initiatives to help CWC member-states manage chemical terrorism.

2 Since the FBI officially closed the investigation in 2010 several biologists and chemists disagree on whether the Bureau got the right perpetrator based on the presence of silicon and tin coating on the anthrax spores. In the opinion of some experts this suggests a greater complexity of manufacturing beyond the scope of what Ivins could do in his lab. Additionally, earlier in the investigation another army research scientist Steven Hatfield was targeted, but later exonerated, with the DOJ paying a \$4.6 million legal settlement to the scientist.

3 For a more detailed discussion of non-state actors and stolen biological agents, see Walsh $(2018,37-41)$.

4 In the US, easily over 2 million people are employed with over 73,000 businesses working across range of biosciences (medicine, agriculture, pharmaceuticals, research (Biotechnology Innovation Organization, 2014).

5 A dirty bomb, otherwise known as a radiological dispersal device (RDD), combines conventional explosives, like dynamite, with radiological material. The regular explosive helps in dispersing the radioactive material.

\section{References}

Ackerman, Gary, and Michelle Jacome. 2018. "WMD Terrorism: The Once and Future Threat". PRISM 7 (3): 22-37.

Albright, David, Paul Brannan, and Andrea S. Stricker. 2010. "Detecting and Disrupting Illicit Nuclear Trade after A.Q. Khan". The Washington Quarterly 33 (2): 85-106. https://doi.org/10.1080/01636601003673857.

Allison, Graham. 2018. "Nuclear Terrorism: Did We Beat the Odds or Change Them?" PRISM | National Defense University 7 (3): 2-21. 
Anderson, David. 2016. Report of the Bulk Powers Review. London: HMSO.

Bajema, Natasha, and Diane DiEuliis. 2017. Peril and Promise: Emerging Technologies and WMD. Washington, DC: National Defense University. Report for 12-13 October 2016 Emergence and Convergence Workshop.

Balatsky, Galya I., and William R Severe. 2019. "Illicit Trafficking of Radioactive and Nuclear Materials". In Nuclear Safeguards, Security, and Nonproliferation, edited by James E. Doyle, 2nd edition, 357-87. Boston: Butterworth-Heinemann. https://doi. org/10.1016/B978-0-12-803271-8.00012-6.

Berger, Sarah. 2015. "What Is ISIS' Chemical Weapons Stockpile? Islamic State Group Has Recruited Experts from across the World to Build Terror Arsenal". International Business Times, November 19.

Binder, Markus K., and Gary A. Ackerman. 2019. "Pick Your POICN: Introducing the Profiles of Incidents Involving CBRN and Non-State Actors (POICN) Database". Studies in Conflict \& Terrorism 0 (0): 1-25. https://doi.org/10.1080/1057610X.2019.1577541.

Binder, Markus K., Jillian M. Quigley, and Herbert F. Tinsley. 2018. "Islamic State Chemical Weapons: A Case Contained By Its Context?" CTC Sentinel 11 (3): 27-32.

Biotechnology Innovation Organization. 2014. "Battelle/BIO State Bioscience Jobs, Investments and Innovation 2014". www.bio.org/articles/battellebio-state-biosciencejobs-investments-and-innovation-2014.

Boyle, Darren. 2015. "ISIS Scientists Set to Wage Chemical and Biological War on West". Mail Online. December 6. www.dailymail.co.uk/news/article-3347671/ISIS-armyscientists-set-wage-chemical-biological-war-West-Experts-warn-weapons-massdestruction-carried-undetected-Europe-Union.html.

Bunn, Matthew, and Scott D. Sagan, eds. 2016. Insider Threats. 1st edition. Ithaca; London: Cornell University Press.

Butler, Desmond. 2015. "Nuclear Black Market Seeks IS Extremists". AP NEWS, October 7. https://apnews.com/article/9f77a17c001f4cf3baeb28990b0d92eb.

Butler, Robin. 2004. Review of Intelligence on Weapons of Mass Destruction Report of a Committee of Privy Counsellors. London: The Stationary Office. https://fas.org/irp/ world/uk/butler071404.pdf.

Carlson, Robert. 2003. "The Pace and Proliferation of Biological Technologies". Biosecurity and Bioterrorism: Biodefense Strategy, Practice, and Science 1 (3): 203-14. https:// doi.org/10.1089/153871303769201851.

Carus, Seth. 2000. "The Rajneeshees". In Toxic Terror: Assessing Terrorist Use of Chemical and Biological Weapons, edited by Jonathan B. Tucker, Steven E. Miller, and Sean M. Lynn-Jones, Illustrated edition. Cambridge, MA: MIT Press.

Caves, John, and Seth Carus. 2014. The Future of Weapons of Mass Destruction: Their Nature and Role in 2030. Washington, DC: Center for the Study of Weapons of Mass Destruction.

Chyba, Christopher F. 2006. "Biotechnology and the Challenge to Arms Control". Arms Control Today, October 2006.

Cirincione, Joe, and Geoff Wilson. 2015. "Why I Fear the Dirty Bomb and You Should Too". War on the Rocks, November 10. https://warontherocks.com/2015/11/ why-i-fear-the-dirty-bomb-and-you-should-too/.

Clapper, James R. 2016. "Statement for the Record Worldwide Threat Assessment of the US Intelligence Community”. www.odni.gov/files/documents/SASC_Unclassified_ 2016_ATA_SFR_FINAL.pdf.

Clarke, Michael. 2013. "Pakistan and Nuclear Terrorism: How Real Is the Threat?" Comparative Strategy 32 (2): 98-114. https://doi.org/10.1080/01495933.2013.773700. 
Cogan, Charles. 2004. "Hunters Not Gatherers: Intelligence in the Twenty-First Century". Intelligence and National Security 19 (2): 304-21. https://doi.org/10.1080/0268452042 000302010.

Cornish, Paul. 2007. The CBRN System: Assessing the Threat of Terrorist Use of Chemical, Biological, Radiological and Nuclear Weapons in the United Kingdom. London: Chatham House (The Royal Institute of International Affairs). www.chathamhouse.org/sites/ default/files/public/Research/International\%20Security/cbrn0207.pdf.

Danzig, Richard, Marc Sageman, Terrance Leighton, Lloyd Hough, Hidemi Yuki, Rui Kotani, and Zachary M. Hosford. 2012. Aum Shinrikyo: Insights into How Terrorists Develop Biological and Chemical Weapons. Washington, DC: Center for a New American Security. www.jstor.org/stable/resrep06323.

Doornbos, Harald, and Jenan Moussa. 2014. "Found: The Islamic State's Terror Laptop of Doom”. Foreign Policy (blog). August 28. https://foreignpolicy.com/2014/08/28/ found-the-islamic-states-terror-laptop-of-doom/.

Elvey, Suz. 2015. "Timebomb: The Biological Weapons AND the Islamists Who Will Arm Them Are ALREADY Here". Express, December 6. www.express.co.uk/news/ uk/624620/Warning-ISIS-Daesh-chemical-weapons-attack-West.

Fey, Marco. 2017. 3D Printing and International Security: Risks and Challenges of an Emerging Technology. Frankfurt: Peace Research Institute Frankfurt.

Flood, Philip. 2004. Report of the Inquiry into Australian Intelligence Agencies. Canberra: AGPS.

Gentry, John A., and Joseph S. Gordon. 2019. Strategic Warning Intelligence: History, Challenges, and Prospects. 1st edition. Washington, DC: Georgetown University Press.

Gibbons-Neff, Thomas. 2017. "ISIS Drones Are Attacking U.S. Troops and Disrupting Airstrikes in Raqqa, Officials Say". Washington Post, June 6. www.washingtonpost.com/ news/checkpoint/wp/2017/06/14/isis-drones-are-attacking-u-s-troops-and-disruptingairstrikes-in-raqqa-officials-say/.

Habegger, Beat. 2010. "Strategic Foresight in Public Policy: Reviewing the Experiences of the UK, Singapore, and the Netherlands". Futures 42 (1): 49-58. https://doi. org/10.1016/j.futures.2009.08.002.

Hoffman, Wyatt, and Tristan A. Volpe. 2018. "Internet of Nuclear Things: Managing the Proliferation Risks of 3-D Printing Technology". Bulletin of the Atomic Scientists 74 (2): 102-13. https://doi.org/10.1080/00963402.2018.1436811.

Hvistendahl, Mara. 2016. “3D Printers Vulnerable to Spying”. Science 352 (6282): 132-3. https://doi.org/10.1126/science.352.6282.132.

Ivanova, Kate, and Todd Sandler. 2006. "CBRN Incidents: Political Regimes, Perpetrators, and Targets". Terrorism and Political Violence 18 (3): 423-48. https://doi. org/10.1080/09546550600752014.

Kallenborn, Zachary, and Philipp C. Bleek. 2018. "Swarming Destruction: Drone Swarms and Chemical, Biological, Radiological, and Nuclear Weapons". The Nonproliferation Review 25 (5-6): 523-43. https://doi.org/10.1080/10736700.2018.1546902.

Kaplan, David K., and Andrew Marshall. 1996. The Cult at the End of the World: Incredible Story of Aum. 1st edition. London: Crown.

Kelly, Robert E. 2017. Is Three-Dimensional (3-D) Printing a Nuclear Proliferation Tool? Stockholm: SIPRI.

Koblentz, Gregory D. 2009. Living Weapons: Biological Warfare and International Security. 1st edition. New York: Cornell University Press.

Kouzes, Richard T., Edward R. Siciliano, James H. Ely, Paul E. Keller, and Ronald J. McConn. 2008. "Passive Neutron Detection for Interdiction of Nuclear Material at 
Borders". Nuclear Instruments and Methods in Physics Research Section A: Accelerators, Spectrometers, Detectors and Associated Equipment 584 (2): 383-400. https://doi. org/10.1016/j.nima.2007.10.026.

Kroenig, Matthew, and Tristan Volpe. 2015. "3-D Printing the Bomb? The Nuclear Nonproliferation Challenge". The Washington Quarterly 38 (3): 7-19. https://doi.org/10.10 80/0163660X.2015.1099022.

Maurer, Stephen M., ed. 2009. WMD Terrorism: Science and Policy Choices. Cambridge, MA: The MIT Press.

Mauroni, Albert. 2019. "The Rise and Fall of Counterproliferation Policy". The Nonproliferation Review 26 (1-2): 1-15. https://doi.org/10.1080/10736700.2019.1593691.

McIntosh, Christopher, and Ian Storey. 2018. "Between Acquisition and Use: Assessing the Likelihood of Nuclear Terrorism”. International Studies Quarterly 62 (2): 289-300. https://doi.org/10.1093/isq/sqx087.

Miller, Seumas. 2006. "Collective Moral Responsibility: An Individualist Account”. Midwest Studies in Philosophy 30 (1): 176-93. https://doi.org/10.1111/j.1475-4975.2006.00134.x.

-2018. Dual Use Science and Technology, Ethics and Weapons of Mass Destruction. Springer Briefs in Ethics. Springer International Publishing. https://doi.org/10.1007/ 978-3-319-92606-3.

Miller, Seumas, and Michael J. Selgelid. 2007. "Ethical and Philosophical Consideration of the Dual-Use Dilemma in the Biological Sciences". Science and Engineering Ethics 13 (4): 523-80. https://doi.org/10.1007/s11948-007-9043-4.

Mowatt-Larssen, Rolf. 2010. “Al Qaeda Weapons of Mass Destruction Threat: Hype or Reality?” Belfer Center for Science and International Affairs (blog). January 2010. www.belfercenter.org/publication/al-qaeda-weapons-mass-destruction-threat-hype-orreality.

Mueller, John. 2019. "Nuclear Weapons Don't Matter". January 29. www.foreignaffairs. com/articles/2018-10-15/nuclear-weapons-dont-matter.

Mugavero, Roberto, Stanislav Abaimov, Federico Benolli, and Valentina Sabato. 2018. "Cyber Security Vulnerability Management in CBRN Industrial Control Systems (ICS)". International Journal of Information Systems for Crisis Response and Management 10 (April): 49-78. https://doi.org/10.4018/IJISCRAM.2018040103.

National Academies of Sciences, Engineering, and Medicine, Policy and Global Affairs, Committee on Science, Technology, and Law, and Committee on Dual Use Research of Concern: Options for Future Management. 2017. Dual Use Research of Concern in the Life Sciences: Current Issues and Controversies. Washington, DC: National Academies Press (US). www.ncbi.nlm.nih.gov/books/NBK458491/.

National Defense University. 2003. "Toward a National Biodefense Strategy: Challenges and Opportunities, April 2003". Center for Counterproliferation Research, National Defense University, Washington, DC. https://web.archive.org/web/20130221101014/ www.ndu.edu/centercounter/CCR\%202003.pdf.

Petro, James B., and Seth Carus. 2005. "Biological Threat Characterization Research: A Critical Component of National Biodefense". Biosecurity and Bioterrorism: Biodefense Strategy, Practice, and Science 3 (4): 295-308. https://doi.org/10.1089/bsp.2005. 3.295.

Pita, René. 2007. “Assessing Al-Qaeda's Chemical Threat”. International Journal of Intelligence and CounterIntelligence 20 (3): 480-511. https://doi.org/10.1080/08850 600701249824.

Rathore, Shahzeb Ali. 2016. "Is the Threat of ISIS Using CBRN Real?" Counter Terrorist Trends and Analyses 8 (2): 4-10. 


\section{Patrick F. Walsh}

Rid, Thomas. 2011. “Cyber War Will Not Take Place”. Journal of Strategic Studies 35 (1): 5-32.

Rosenau, William. 2001. “Aum Shinrikyo's Biological Weapons Program: Why Did It Fail?" Studies in Conflict \& Terrorism 24 (4): 289-301. https://doi.org/10.1080/10576100 120887.

Rosoff, Heather, and Detlof Von Winterfeldt. 2007. "A Risk and Economic Analysis of Dirty Bomb Attacks on the Ports of Los Angeles and Long Beach”. Risk Analysis 27 (3): 533-46. https://doi.org/10.1111/j.1539-6924.2007.00908.x.

Shaw, Robert. 2017. "3D Printing: Bringing Missile Production to a Neighborhood Near You | NTI”. NTI (blog). February 22. www.nti.org/analysis/articles/3dprinting-bringingmissile-production-neighborhood-near-you/.

Shea, Dana A., and Sarah A. Lister. 2003. The BioWatch Program: Detection of Bioterrorism. Washington, DC: Congressional Research Service.

Sims, Alyssa. 2018. "The Rising Drone Threat from Terrorists". Georgetown Journal of International Affairs 19 (November): 97-107. https://doi.org/10.1353/gia.2018.0012.

SSCI. 2004. Report on the US Intelligence Community's Pre War Intelligence Assessments on Iraq. Washington, DC: US Government Printing Office.

Strack, Columb. 2017. "The Evolution of Islamic State's Chemical Weapons". CTC Sentinel 10 (9): 19-24.

Tenet, George. 2007. At the Center of the Storm. 1st edition. New York: HarperCollins.

Tucker, Jonathan B., Steven E. Miller, and Sean M. Lynn-Jones. 2000. Toxic Terror: Assessing Terrorist Use of Chemical and Biological Weapons. Cambridge, MA: MIT Press.

van de Velde, James R. 2010. "The Impossible Challenge of Deterring 'Nuclear Terrorism' by Al Qaeda". Studies in Conflict \& Terrorism 33 (8): 682-99. https://doi.org/10.1080/ 1057610X.2010.494155.

Vavra, Shanon. 2019. “'This Isn't IAD 2.0': NSA's New Cybersecurity Directorate Plots Its Mission". Cyberscoop (blog). July 25. www.cyberscoop.com/nsa-cybersecuritydirectorate-neal-ziring-dave-frederick/.

Vogel, Kathleen M. 2008. "Biodefense". In Biosecurity Interventions Global Health and Security in Question: Global Health and Security in Practice, edited by Andrew Lakoff and Stephen Collier, 1st edition, 227-55. New York: Columbia University Press.

- 2013. "Necessary Interventions: Expertise and Experiments in Bioweapons Intelligence Assessments". Science, Technology and Innovation Studies 9 (2): 61-88.

Walsh, Patrick F. 2016. "Managing Emerging Health Security Threats since 9/11: The Role of Intelligence". International Journal of Intelligence and CounterIntelligence 29 (2): 341-67. https://doi.org/10.1080/08850607.2016.1121048.

- 2018. Intelligence, Biosecurity and Bioterrorism. Intelligence, Biosecurity and Bioterrorism. London: Palgrave Macmillan. https://doi.org/10.1057/978-1-137-51700-5.

- 2021. Intelligence Leadership and Governance. Abingdon: Routledge.

Walsh, Patrick F., and Seumas Miller. 2016. "Rethinking 'Five Eyes' Security Intelligence Collection Policies and Practice Post Snowden". Intelligence and National Security 31 (3): 345-68. https://doi.org/10.1080/02684527.2014.998436.

Warrick, Joby. 2017. "Use of Weaponized Drones by ISIS Spurs Terrorism Fears". Washington Post, February 21, sec. National Security. www.washingtonpost.com/world/ national-security/use-of-weaponized-drones-by-isis-spurs-terrorism-fears/2017/02/21/9 d83d51e-f382-11e6-8d72-263470bf0401_story.html.

Weiss, Leonard. 2015. “On Fear and Nuclear Terrorism”. Bulletin of the Atomic Scientists 71 (2): 75-87. https://doi.org/10.1177/0096340215571909. 
Zhang, Lisa, and Gigi Kwik Gronvall. 2020. "Red Teaming the Biological Sciences for Deliberate Threats". Terrorism and Political Violence 32 (6): 1225-44. https://doi.org/1 0.1080/09546553.2018.1457527.

Zöller, Lothar, and Gelimer H. Genzel. 2018. "The Role of Bioforensics in Medical Bio-Reconnaissance". In Defence against Bioterrorism, edited by Vladan Radosavljevic, Ines Banjari, and Goran Belojevic, 177-87. NATO Science for Peace and Security Series A: Chemistry and Biology. Dordrecht: Springer Netherlands. https://doi. org/10.1007/978-94-024-1263-5_13. 